\title{
EOSINOPHILIC GRANULOMATOSIS WITH POLYANGIITIS MIMICKING GUILLAIN-BARRÉ SYNDROME
}

Vanessa de Quadros Martins ${ }^{1, \star}$, Jean Paulo Veronese de Souza1, Guilherme Stüker², Roberta Casanova Wilhelms', Camila Schafer ${ }^{1}$, Deise Marcela Piovasan', Bárbara Mendes da Silva', Marcelo Maltchik', lloite Maria Scheibel ${ }^{3}$, Markus Bredemeier $^{1}$

1.Hospital Nossa Senhora da Conceição, Porto Alegre (RS), Brazil. 2.Hospital São Lucas da PUCRS, Porto Alegre (RS), Brazil. 3.Hospital da Criança Conceição, Porto Alegre (RS), Brazil.

*Corresponding author: vanessamartinsmed@gmail.com

\section{BACKGROUND}

Eosinophilic granulomatosis with polyangiitis (EGPA) is a systemic vasculitis characterized by the onset of asthma, eosinophilia, neuropathy, migratory pulmonary infiltrates (may be transient), abnormalities of paranasal sinuses and biopsy proven increased extravascular eosinophilic infiltrate. According to the American College of Rheumatology (ACR 1990), at least four of these features are needed to fulfill the diagnostic criteria. As far as we know, there are only three case reports of EGPA mimicking Guillain-Barré syndrome (GBS). Considering that, we herein present a case of EGPA whose first manifestation was a severe ascending peripheral polyneuropathy.

\section{CASE REPORT}

A 66 years-old female patient, with a history of asthma diagnosed 3 years ago, came to the emergency department due to progressive ascending weakness of inferior limbs initiated 2 weeks before. At admission, she reported recent emergence of weakness of superior limbs and dysphagia. On physical examination, she had grade 2 strength in all four limbs. Initial lab evaluation showed a count of eosinophils equal to 3,845 eosinophils/ $\mu \mathrm{L}$, hemoglobin: $12.7 \mathrm{mg} / \mathrm{dL}$; leukocytes: 12,990; lymphocytes: 987 ; platelets: 338,000; serum urea: $25 \mathrm{mg} / \mathrm{dL}$; creatinine: $0.48 \mathrm{mg} / \mathrm{dL}$; potassium: $4.2 \mathrm{mEq} / \mathrm{L}$; calcium: $8.5 \mathrm{mg} / \mathrm{dL}$; magnesium: $1.9 \mathrm{mg} / \mathrm{dL}$; aspartate aminotransferase (AST): $27 \mathrm{U} / \mathrm{L}$; alanine-aminotransferase (ALT): $24 \mathrm{U} / \mathrm{L} ; \mathrm{LDH}$ : $459 \mathrm{U} / \mathrm{L}$; CK-NAC: $328 \mathrm{U} / \mathrm{L}$; C-reactive protein: $57.2 \mathrm{mg} / \mathrm{L}$ and the erythrocyte sedimentation rate $26 \mathrm{~mm} / \mathrm{h}$. Albendazole and ivermectin were prescribed to treat empirically the eosinophilia. In view of the diagnostic hypothesis of GBS and the severity of the condition, methylprednisolone pulse therapy was also indicated ( $1 \mathrm{~g} /$ day during 5 days). The electrophysiological study showed asymmetric subacute axonal polyneuropathy associated with acute neuronal impairment of proximal muscles and minimal collateral axonal reinnervation, compatible with GBS, but liquor without protein-cytological dissociation. Computed tomography of paranasal sinuses demonstrated significant inflammatory signs. Testing for ANCA was positive (titer, 1:40), presenting a perinuclear pattern. Treatment with prednisone $60 \mathrm{mg} /$ day and pulses of intravenous cyclophosphamide were initiated after completion of the pulse steroid therapy. The patient then presented progressive reduction of symptoms, been able to walk without assistance and demonstrating grade IV strength in inferior limbs after 2 weeks of initiation of therapy. Treatment with pulses of intravenous cyclophosphamide and oral prednisone (in progressively decremental doses) will follow in an outpatient basis.

\section{CONCLUSION}

The present report describes a rare case of EGPA simulating acute demyelinating syndrome, with excellent initial response to immunosuppressive therapy. 